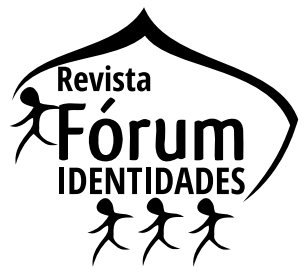

\title{
LITERATURA BRASILEIRA CONTEMPORÂNEA: DA MULHER ÀS MULHERES ${ }^{1}$ \\ BRAZILIAN LITERATURE BY FEMALE AUTHORS: FROM WOMAN TO WOMEN
}

\author{
Antonio de Pádua Dias da Silva²
}

\begin{abstract}
Resumo: O objetivo deste artigo é problematizar relações de gênero pelas quais mulheres enveredaram na e pela literatura, tomando o valor "família" como baliza. Parto de uma linha temporal demarcada por um antes e um depois dos anos 1980. Desenvolvo a hipótese de que parte da literatura de mulheres antes dos anos 80 continha traços da noção de mulher como sujeito uniforme, concepção de sujeito iluminista; já no pós 80 , há um centramento na diversidade, no desfazer os gêneros considerando as mulheres em uma multidão. Metodologicamente, analiso o uso da linguagem dos textos revistos, defendendo a concepção de anti-arte como marca afirmativa na construção das escritas de mulheres que falam sobre mulheres. Anti-arte advém, nos textos discutidos, como performance linguística que se constrói como um modo específico de problematizar questões de mulheres.
\end{abstract}

Palavras-chave: Literatura de Mulher. Tradição. Cânone. Anti-arte. Família.

\begin{abstract}
The purpose of this article is to question the scope of gender relations that women have considered in/through literature, having the family value as parameter. This work was carried out considering a period of time before and after 1980. I develop the hypothesis that part of literature by female authors before the 80 's contained traces of the notion of woman as uniform individual, conception of enlightening individual; after the 80 's, there is a convergence on diversity, disregarding genders by considering women in a crowd. Methodologically, I analyze the use of the language of the revised texts, defending the concept of anti-art as an affirmative mark in the construction of the writings of women who talk about women. Anti-art is defended as an affirmative mark in the construction of writings of today's women's literature.
\end{abstract}

Keywords: Woman's Literature. Tradition. Canon. Anti-Art. Family.

\footnotetext{
${ }^{1}$ Artigo recebido em 10 de fevereiro de 2021 e aceito em 30 de março de 2021.

2 Professor de Literatura e Estudos de Gênero na Universidade Estadual da Paraíba. Doutor em Letras (UFAL) com estágio de pós-doutorado (UFRJ). Membro do GT Homocultura e Linguagens (Anpoll). Autor de Mulheres representadas na literatura de autoria feminina - vozes de permanência e poética da agressão (2011). ORCID: https://orcid. org/0000-0002-6241-4466. E-mail: magister.padua@hotmail.com.
} 


\section{Introdução}

A produção escrita de mulheres, no Brasil, ao longo do século XX, recebeu um amplo tratamento acadêmico: caso o leitor não invista em uma profunda revisão da fortuna crítica, correrá o risco de dizer o óbvio, de copiar ideias sem antes mesmo tê-las conhecido. Isso porque já se tem produzido bastante - mas não o necessário ainda - nesse campo de conhecimento. Na literatura, então, o próprio Seminário Mulher e Literatura - mantido por gestoras do Grupo de Trabalho A Mulher na Literatura ${ }^{3}$ - é uma vitrine de teorias, críticas, leituras e perspectivas sobre mulheres nas culturas, nas artes, nos discursos, nas literaturas.

Apesar de ter optado, neste texto, por discutir a produção literária brasileira de autoria feminina, distancio-me das problemáticas já tornadas relevantes, ${ }^{4}$ explicitadas ou ainda em construção por estudiosas e estudiosos desse campo de conhecimento. Atenho-me a uma produção literária de mulheres sincronizada na década de 1980 até 2017. Como critério de seleção do corpus, estabeleço um recorte específico referente a esse período. $O$ tratamento dado às escritoras, aqui, segue o critério de um mesmo valor para as escrituras, apesar de ter ciência que as linguagens são diferentemente trabalhadas, que os estilos são bastante personalizados, que é possível perceber obras com maior esforço de (re)criação em relação a outras. Mas tudo isso não me convida a entender obras valoradas diferentemente. Elas são apenas compreendidas de formas diferentes, porque de autoria, estilo e intenções diferentes.

Esse modo de abordagem me dá uma dimensão mais global e plural das tendências de produção das escritas criativas de mulheres no Brasil, sobretudo nas últimas quatro décadas. É evidente que investir em um modo de abordagem que planifica as escritas com um mesmo critério de valor faz que a ideia lançada encontre várias outras contrárias e que buscam, na base interpretativa, contradizer o que levanto aqui como argumento sustentador da hipótese de trabalho. Isso ocorre porque as condições do faz̧er literário e do dizer sobre este fazer, envolvendo toda uma sistemática centrada no mercado, no público leitor, no lugar de onde vem e fala $\mathrm{o} / \mathrm{a}$ autor, nas discussões críticas alimentadas pela academia determinam, de certo modo, um modelo de arte, de literatura, de escrita, de texto e autor para ser lido (em escolas) e representativo da cultura e da língua(gem) brasileiras. Assim, então, estabelece-se uma espécie de cânone ou visão canônica do evento em pauta.

\footnotetext{
${ }^{3}$ O Grupo de Trabalho (GT) da Associação Nacional de Programas de Pós-Graduação em Letras e Linguísticas (Anpoll), A Mulher na Literatura, foi criado no ano de 1984.

${ }^{4}$ A exemplo de teorias de base feministas (Tendências e impasses: o feminismo como crítica da cultura, organizado por Heloísa Buarque de Holanda); do corpo feminino (Que corpo é esse? O corpo no imaginário feminino, de Elódia Xavier; O corpo em revista: olhares interdisciplinares, organizado por Izabel Brandão); do resgate de autoras (Dicionário crítico de escritoras brasileiras, organizado por Nelly Novaes Coelho).
} 
O que foge a esse esquema ou sai do roteiro desse sistema, rasurando-o, recebe várias tarjas e rótulos, muitas vezes com a pecha negativa: Moutinho (2001) trabalha com a noção de piroso como uma arte "falsa", relacionada ao kitsch; este, por sua vez, recebe um tratamento estético relacionado, na visão canônica, ao mau gosto, embora problematizado numa chave de leitura afirmativa; Link (2004) usa o termo trash como sinônimo de lixo ou bizarro, no campo da arte, ainda assim esse conceito é reafirmado positivamente pelo autor; Khote (1994) se apropria da noção de trivial e, de modo engessado, interpreta produções literárias de massa, por exemplo, como mal exemplo literário porque, segundo afirma, resvalam para a superficialidade das relações sociais; Faciolince (2000), por sua vez, aborda a ideia com a categoria basura, ou lixo, e aponta para escritas não fundadas na base da tradição; por fim, Oiticica (1986) discute o termo anti-arte como categoria de análise e conceituação de obras que fogem do padrão canônico, sendo arte na contramão do conceito.

Parto de um problema em que se sustenta a minha leitura dos textos de autoria feminina a ser exposta mais adiante: mulheres que escrevem no tempo atual, e que tiveram seus inícios de escrita em condições socioculturais gestadas a partir da década de 80 do século passado, tendem a centrar seus temas e suas escritas em uma imago que perturba as escritas de suas antecessoras, deixam nítida a distinção entre os modos de figurar mulheres na literatura, pois antes desse marco temporal o modelo propagado de mulher (cartesiano, iluminista) era o sustentado por escritoras. As autoras que se afastavam do modelo cartesiano, a exemplo de Cassandra Rios, Adelaide Carraro, Márcia Denser, Hilda Hilst, eram lidas e interpretadas como menores e transgressoras, porque borravam a concepção clássica de literatura. ${ }^{5}$

Posteriormente a esse modo de dizer, percebe-se um investimento na pluralidade, nos vários modelos de mulheres capazes de habitar os cenários socioculturais representados, com a possibilidade de nem mesmo serem exibidas em sua "plenitude" cultural, mas continuando in progress, em processo, em construção, em devir, como apontam coordenadas teóricas mais em uso nos dias de hoje. Isso significa que houve um avanço nos modos de figurar, representar, trazer à tona, na literatura, as mulheres: passou-se de um estágio centrado nA Mulher ${ }^{6}$ e abriu-se espaço de reflexão para as mulheres. O modelo branco, burguês, cristão sai de circuito em nome dos vários modelos de mulheres: brancas, negras, índias, amarelas, pobres, faveladas, presidiárias, agricultoras, periféricas, desempregadas, lésbicas, mulheres trans, mães, solitárias, analfabetas etc.

\footnotetext{
${ }^{5}$ Apesar de, em momentos posteriores, elas terem alcançado um público leitor que compreende o modo de fazer literário como afirmativo, a exemplo de Hilda Hilst que ganha toda uma fortuna crítica afirmativa em torno de sua obra, seja ela paródica, erótica, existencialista.

${ }^{6}$ As iniciais maiúsculas aludem ao singular do modelo de mulher adotado, planificado, fora do escopo das diferenças porque é arquetípico. Pluralizado, alude às diversas diferenças: sociais, étnicas, de gênero, escolaridade etc.
} 
Diante do cenário cultural que favorece a emergência de vários tipos de sujeitos, e problematizando-o na e pela literatura de autoria feminina, objetivo, então, refletir sobre dois modelos de mulheres que circulam nas obras de autoria feminina, do tempo aqui já recortado: quatro últimas décadas. $O$ valor família é o mote dado para perceber o pensamento de mulheres que escrevem sobre mulheres em suas diversas relações de afeto e modos de re-conhecer a instituição família.

Há discursos, porém, que, vinculados ainda a modos de entender a literatura dentro de um escopo geral de estranhamento ou problematização linguística - diante dos mesmos textos que trago à tona - dizem-nos menores ou destituídos de uma suposta artisticidade presente nas escritas que se querem mais canônicas, mais modelo único. Surge, então, o aspecto anti-arte dessa produção. Aqui, discuto a noção de anti-arte, apropriada por mim para entendê-la diretamente vinculada à produção literária de mulheres, num escopo semântico afirmativo, que valora essa produção sem questioná-la e sem compará-la a modelos majoritários. Para Oiticica (1986), essa manifestação artística não se vincula às versões estéticas canônicas porque aborda ideias coletivas, não centradas na dinâmica existencial de grupos hegemônicos e, mesmo se isso ocorresse (na literatura), a configuração ou representação estaria para uma relação crítica, problematizada. A linguagem da literatura nessa perspectiva rasura a gramática, fere o dicionário, destoa das lições de moral e do "bom tom" culturais. Toma-a como um modo de expressão da cultura e, se anti-arte, apenas no sentido de, artisticamente, contrariar o modelo homogêneo e iluminista de entender arte.

\section{O "modelo" de Helena Parente Cunha}

Quando procuro entabular uma discussão no sentido de entender o pensamento de uma época que reprimia desejos e educava a mulher para a sociedade (machista, patriarcal), vêm-me à mente a escrita de autoras como Helena Parente Cunha (1998), estudada por vários pesquisadores do País, e com ela, outras escritoras como Júlia Lopes de Almeida, Clarice Lispector, Raquel de Queiroz, Ana Maria Machado, Adélia Prado, Zulmira Ribeiro, dentre outras, que, à luz de Xavier (1998), configuraram personagens que foram assujeitadas ao regime patriarcal mas, em alguns momentos, mesmo timidamente, procuraram rasurar esse regime na tentativa de encontrar rotas de fuga capazes de torná-las mais autônomas, mais emancipadas e liberadas de pesadas cargas de valores ideológicos que reiteravam o machismo. Vejamos um conto desta autora: 


\section{CERTA CONTA}

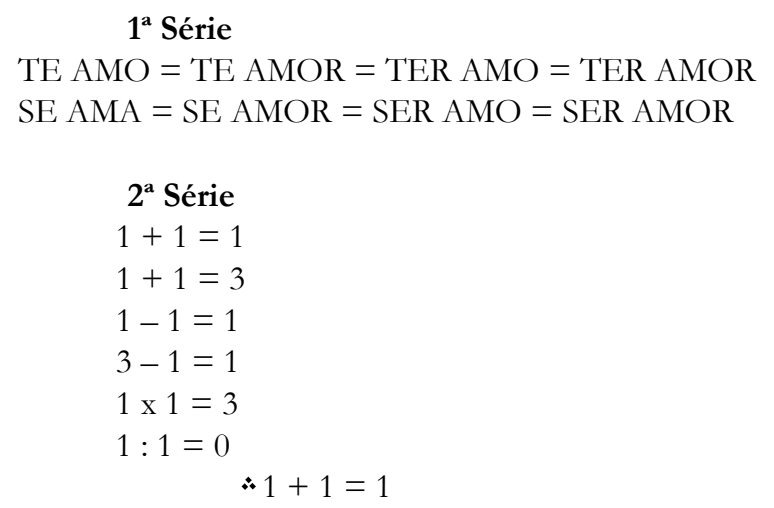

O texto em si exige três considerações a serem feitas, dentro da perspectiva com a qual trabalhamos. A primeira delas relaciona-se ao fato de se tratar de uma narrativa que rasura a noção ou conceito clássico que se tem do que seja conto ou narrativa literária. Tradicionalmente escrita em prosa, a narrativa que se mostra exibe um modo diferente, uma linguagem autêntica para construir uma estória. O enredo, logo, por essa visão, soa bastante enriquecedor por aglutinar em si a segunda consideração a ser feita, a saber, o uso da linguagem matemática (as quatro operações básicas da matemática, e seus símbolos, construindo o texto em discussão) que estrutura um enredo verticalizado, como se se tratasse de um poema (cuja leitura se dá num eixo de cima para baixo) e não de uma narrativa (cuja leitura se dá num eixo horizontal).

A terceira consideração a que me refiro trata-se da condição de sujeito implícita no texto: a percepção de mulher, no singular, reitera a noção de sujeito do iluminismo, conforme apontamento de Hall (1997), ou seja, a utilização das operações básicas da matemática para operar no texto literário uma discussão em torno da mulher é bastante sintomática, vez que, por se tratar de linguagem exata ou de uma ciência exata, a representação feminina de que se impregna o conto é bastante feliz neste sentido: a mulher ali representada é toda ela uma planificação ou reiteração dA Mulher, contrariamente à noção de mulheres.

Para Hall (1997), o sujeito do iluminismo era centrado, inteiro, natural, essencial, conforme a visão cartesiana entendida à época a que se refere o texto. As mulheres, fossem elas da realidade empírica ou da literatura, ancoradas por esse tipo de pensamento, assim também foram tratadas e atuam nos cenários textuais. Binariamente existindo, polarizadas numa dicotomia que torna um sujeito maior e mais forte (o homem) do que o outro (a mulher), as possibilidades da pluralidade e da reinvenção de si (TOURAINE, 2010), logo, eram alternativas impensáveis, dificilmente levadas à tona dentro das estruturas de poder assentadas sob 
regimes cartesianos. Era em estruturas assim que o sujeito encontrava toda uma sistemática de equilíbrio do mundo e de psique a partir da imagem fálica, do homem, em que o modelo de mulher era orientado pela imagem masculina.

Ao adotar esse modelo esquemático, elabora-se uma noção de literatura também reiteradora desse tipo de sujeito. A literatura autônoma - centrada em esquemas táticos de linguagem cujo epicentro, segundo os estudiosos adeptos dessa concepção afirmam, é o trabalho e sua linguagem -, no dizer de Cortázar (2006), coloca em primeiro plano o modo de dizer e torna secundário o quê dizer. Os estudos sobre a autonomia artística ou literária facilmente colocariam o texto "Certa conta", de Helena Parente Cunha, no rol dessa linguagem hermética, difícil, complexa, codificada, diria até, numa versão mais ousada e pertinente às tecnologias androides com as quais trabalhamos hoje, criptografadas. A criptografia, então, residiria no étimo do termo, a saber, "escrita secreta", vez que o termo é oriundo da junção dos termos gregos kruptós (designativo de secreto ou oculto) e graphia (interpretante de escrita). ${ }^{7}$

Elaborado em uma chave de leitura cujo acesso à decifração se faz por um domínio do código (artístico, teórico, crítico), previsto pela educação tradicional apenas às pessoas iniciadas, textos como "Certa conta" só podiam falar em um modelo de pessoa: A Mulher. Esta, também social e culturalmente codificada em linguagem que só a interpreta nas funções mulher (do marido), mãe (de filhos com o marido), heterossexual (o "outro" do homem, passiva), enlaçando-se com homem de mesmo grupo étnico (branco), social (detentor de bens) e religioso (cristão). Este último, então, é de grande importância nos contextos a que faço referência, porque a moral que permeia as sociedades patriarcais, como aconteceu no Brasil, encontra respaldo nos costumes e valores judaico-cristãos que, ao invés de problematizarem as pessoas em seus gêneros, simplificam-nas, arrolando-as em scripts sociais que as fazem funcionar conforme as regras que devem performativizar. ${ }^{8}$

Toda a narrativa de Helena Parente Cunha parece assentar-se nessa chave de leitura, apesar de não constituir, por assim dizer, um modelo fixo, engessado, porque outros aspectos linguísticos estão implicados também nas narrativas da autora e que não são trazidos à tona nesse momento. Mesmo diante de uma narrativa mais recente da autora em tela, o livro de minicontos Falas e falares

\footnotetext{
${ }^{7}$ Apesar de o sentido de criptografia, hoje, estar associado a um mecanismo de segurança que torna invulnerável a mensagem escrita ou codificada em redes sociais como o whatsapp, aproprio-me do termo em sua base etimológica, sobretudo no aspecto que significa essa escrita "oculta", nas entrelinhas, no discurso dos textos.

${ }^{8}$ Performativizar, aqui, no sentido atribuído por Butler (2003), aquele em que as pessoas reproduzem modelos de gênero pela constante e ininterrupta imitação. Logo, o gênero binário, por essa perspectiva, só continua sendo binário, e não diverso, pela reprodução performática dos sujeitos que, desde a mais tenra educação, são levados a internalizar discursos de ordem que alocam as pessoas em apenas dois gêneros engessados - masculino e feminino - sem possibilidade alguma de rasura, de ser possível borrar as fronteiras desta ordem.
} 
(2011), percebe-se que, con-fundindo valores, percepções e modos de ser e estar no mundo como mulher, a dominante na contística de Helena Cunha é a linguagem criptografada para problematizar mulheres modelares. A escritora traz à tona esse tipo de sujeito como modo de denunciar regimes rígidos de gênero, optando pelo uso da linguagem estranha, pouco comum, desautomatizada. Vejamos um conto na íntegra:

\section{Elas e eles}

„,mulher, me traga meu prato de comida, mulher lave minha camisa, mulher este feijão está sem sal, mulher, venha deitar na minha cama „,ela sorria e levava e lavava e temperava e deitava e

„os canteiros do jardim se dançavam em pétalas e gotas de sol quando ela vinha com suas águas e cuidados

„,mãe, eu já disse que não gosto dessa sobremesa, mãe eu já disse que você tem que anotar o nome das pessoas que me telefonam, mãe, eu já disse mas você não me ouve, mãe, eu não tenho que dar conta de minha vida para você, mãe, eu não quero que você me faça perguntas

„,ela sorria, ela media o açúcar, ela anotava os nomes, ela ouvia, ela não perguntava e

„,o passarinho entrava e saía da gaiola e dançava na palma da mão aberta para vôos e caminhos

„,vovó, eu não quero ir para a escola hoje, vovó eu quero ir na pracinha agora, vovó eu não quero mais que você me conte estórias de fadas e palácio encantado, vovó, eu quero brincar de macaquinho nas suas costas

„,ela sorria, ela não ia, ela ia, ela não contava, ela sentava no chão e „,ao longe ela ouvia os apelos do mar, perto a voz do búzio no ouvido anunciava horizontes e abismos sem fronteiras „,mulher, este menino quebrou a perna porque você etc, mãe, este menino está com febre porque você etc, será possível, mulher?, será possível, mãe?, é preciso dar limites às crianças „,ela não sorriu, mas

„,ela sorria ao dia que amanhecia e deitou suas águas na dança das pétalas e gotas do sol e abriu a gaiola para a dança dos caminhos do passarinho e não pegou a bolsa nem deixou a mesa posta, mas deixou o portão aberto e

„,sorria e foi pela rua, pela pracinha, e molhou suas águas no sal das águas do mar e foi além do trilho do trem e foi e

„,ela sorria e caminhava a dança dos caminhos e das portas abertas e (CUNHA, 2011, p. 37-38)

O leitor há de perceber que o mote encontrado para a construção do conto funda-se na concepção tradicional da literatura autônoma, correlacionada às artes, cuja linguagem parece voltar-se para si e os sentidos do texto são possíveis de serem estabelecidos, ou devem ser estabelecidos a partir da construção formal do texto em sua linguagem. Observem que existe uma simetria entre o modo de tratar a linguagem no âmbito da ficção e o modo de figurar as pessoas 
em seus gêneros. Logo, ao buscar o uso da linguagem poética, criativa, simbólica, alicerçada em uma construção semântica e numa chave de leitura de carga metafórica e distante das imagens referenciais, opta-se também por alocar nessa figuração contística o modelo binário de mulher como possibilidade apenas naquele lugar (de mãe, parideira e doméstica), com aquela voz (passiva). Suas vontades, seus desejos, suas projeções, a construção de si: tudo parece emudecer na lógica que a torna ilusoriamente afásica, assujeitada. Mas já no fim do "miniconto", quando a mulher encontra para si um modo de viver mais liberto, a timidez cede espaço a um lugar de fala.

O conto em tela exibe, assim como em "Certa conta", uma espécie de linguagem que interpreta esse modelo de mulher no singular, arquetípico (apesar de, na perspectiva arquetípica, haver mais de um modelo como a femme fatale, a Velha Sábia, a Bruxa, a Grande Mãe etc.). O arquetípico aqui soa como algo fixo que derroca outros caminhos de mudanças de rotas. As funções de gerar, cuidar, amamentar, ser dona de casa e servir ao marido na "mesa e na cama" é o protótipo denunciado no conto em tela, apesar de a personagem mulher, a partir do quarto parágrafo, com a entrada do advérbio adversativo mas, dar mostras de cansaço dessa performance.

A literatura de Helena Parente Cunha, dialogando com os contextos culturais, sociais, discursivos, teóricos e de produções artísticas nos dias de hoje, questiona o modelo único de mulher. Quando suas personagens tentam borrar os lugares sociais estabelecidos para as mulheres que devem se comportar como exige a tradição, tacitamente conseguem encontrar vias de escapes, rotas de fuga. Elas desembocam em imagens metafóricas do possível, timidamente buscando tornar-se sujeito de si. A mulher de "Elas e eles" consegue se libertar (não se sabe se provisória ou definitivamente) do marido, da prole, dos netos, mesmo que de forma simbólica: pelo abrir da gaiola e do portão. A saída, a fuga de seu contexto ainda não a torna um sujeito pleno de si, mas apenas uma personagem transgressora e em busca de um empoderamento.

Apesar da personagem, assim como muitas da mesma autora, ser questionada pela voz que narra, de modo implícito, o fato da representação não estabelecer ou alcançar um caminho ou modo de existir pleno fora do padrão previamente agendado para pessoas como as de quem estamos falando, exibe o texto não como faltoso, mas arrojado na proposta de falar de um lugar marcado por uma linguagem criptografada, resistindo ao modelo centrado no homem. Em outros textos, a exemplo de Cida Pedrosa (As filhas de lilith, 2009) e Luiza Romão (Sangria, 2017), para além da crítica feita ao modelo social e de gênero a que as personagens mulheres se encontram presas, a elas são dados caminhos de escapes, utopias de saída, performances, linguagens, atitudes, modos de pen- 
sar que se distanciam do modelo estabelecido, a partir da construção de outros modos de existência feminina. Esses outros modos são exibidos em imagens de mulheres empoderadas, autônomas e resistentes às discursividades que circulam nos lugares sociais. Longe de serem silenciadas por questões dessa ordem, elas buscam reverter pensamentos e propostas, encontrando e demarcando lugares para si nas relações sociais que constroem.

No caso de Pedrosa (2009), o projeto estético do texto citado relaciona imagem e texto, com um número de poemas equivalente ao número de letras do alfabeto latino ou português. Os títulos dos poemas, 26 ao todo, são nomes de mulheres, a exemplo de "angélica", "Berenice", "xênia", todos grafados com inicial minúscula, em linguagem coloquial, evocando assuntos cotidianos relacionados às mulheres envolvidas pela voz do sujeito lírico. Já em Romão (2017) tem-se um projeto literário que se assemelha em um ponto ao de Pedrosa (2009): se nesta o mote foi o abecedário, aqui há o calendário mensal ou "folhinha", especificamente o mês de fevereiro, com 28 dias, para problematizar questões decoloniais ${ }^{9}$ a partir das fases do mês que regram a menstruação das mulheres negras, afrodescendentes. A linguagem também é bastante coloquial, com elementos do cotidiano (incluindo-se o universo linguístico do dia a dia) levados para os poemas para evocar modos de denunciar e de requerer lugares de fala para mulheres.

\section{Rotas de colisão ou mulheres que falam espontaneamente}

No ano de 2006 o GT A Mulher na Literatura publicou, em comemoração aos 25 anos de sua fundação, ocorrido em 2005, Da mulher às mulheres: dialogando sobre literatura, gênero e identidades, uma organização de Ildney Cavalcanti \& Liane Schneider. O título do livro é bastante provocativo e motivador dos estudos empreendidos pelos componentes daquele GT. Percebe-se uma evolução no que diz respeito a concepções teóricas, partindo dA Mulher e desembocando, apenas no momento em que se encontra (sincronizado), nAs Mulheres. Essa percepção teórica e crítica é fruto também de discussões entabuladas na escrita criativa.

A movência de um modelo (A Mulher) para outro (As Mulheres) implica em um modo diferenciado de as autoras deliberarem acerca de suas personagens mulheres, distante de scripts culturais e funcionais que as alocavam em uma única

\footnotetext{
${ }^{9}$ A noção de decolonial surge como proposta interventiva de atores de hoje poderem reverter e subverte a lógica colonialista em curso. Diferente da lógica colonial em sua base, fixa, a proposta decolonial é reverter na atualidade os efeitos da colonização de pensamento, de poder, da natureza, assentada na criticidade e apontando para uma etapa pós-colonial a partir de pessoas afrodescendentes, mulheres, por exemplo. Essa noção é revista também pela ótica da intersecccionalidade das diferenças, quando marcadores sociais como gênero (mulher), cor da pele (negra), grupo social (periférico), escolaridade (mínima), por exemplo, são trazidos à tona para alocar sujeitos em determinados postos de menor ou maior poder. Evidente que a política colonial atribui poder a homens cisgêneros, brancos, escolarizados, cristãos, machistas. A visão decolonial intervêm nesse tipo de paradigma quando critica essas bases e coloca como foco de interesse o sujeito fora dessa dinâmica organizacional, a exemplo de mulheres não heterossexuais, negras, pobres.
} 
posição composta de atributos redutores do sujeito: heterossexual, servidora do marido, parideira e cuidadora do lar. É evidente que essa imago parece ter ficado ainda retida na retina e na rotina cultural de muitas mulheres que habitam as sociedades de hoje, mas também é verdade que apenas uma parcela mínima das mulheres, habitantes de locais bastante enraizados em tradições costumam trazer em si marcas dessa ordem que apostava na sujeição - física, psíquica e simbólica - das mulheres. A regra vigente, logo, aponta para a pluralidade, para a diversidade, para as diferenças, para vários estilos de vida e modos de se subjetivar, ou seja, a construção de si difere "de mulher para mulher", ${ }^{10}$ de grupo étnico para outro e assim por diante, considerando-se os interesses de cada grupo reivindicador.

Avançando em relação ao que vimos na primeira parte deste texto, aqui seremos espectadores de uma constística que anuncia As Mulheres. Escritoras que ambientam estórias no tempo pós anos 80 elaboram outros modos de manter a sua escritura, afastando-se daquelas que denunciaram discursos de base patriarcal e machista. Dialogando com um universo cultural mais próximo das pessoas ordinárias ou cotidianas, falam das mulheres comuns, das tensões, problemas e conflitos sentidos no dia a dia por mulheres diversas, em linguagem informal, coloquial, às vezes rasurando o "valor estético" da linguagem, na comparação com a versão canônica de literatura.

Cida Pedrosa, Conceição Evaristo, Ivana Arruda Leite, Betty Milan, Janaína Azevedo, Cláudia Tajes, Fernanda Young, dentre várias, são autoras que não precisam encontrar rotas de fugas para falar de si, do mundo, do cotidiano. Parece ser imperativo, hoje, reivindicar, lutar, gritar por direitos, propor alternativas para caminhos vistos sem saídas ou com saídas em vias de mão única. As buscas por utopias de saídas, hoje, são mais velozes. Os sujeitos conseguem dialogar com os seus "outros" (não "opositores”) de forma mais democrática. E onde há liberdade, democracia, o espírito das diferenças, da diversidade está sempre presente. Leiamos um conto de Ivana Arruda Leite:

\section{Surdo}

Escrevi um bilhete pro Cícero pedindo que ele viesse o mais rápido possível. O moleque não podia escolher dia pior pra nascer. Em pleno domingo de carnaval. Pelo jeito, vai ser do barulho como o pai. Toninho, o filho de Dora, minha vizinha, correu e entregou o bilhete na mão dele. Ele toca surdo na bateria e o desfile é hoje à noite. A Dora se ofereceu pra me levar pra maternidade mas eu prefiro esperar o Cícero. Pra alguma coisa, o traste tem que servir. Ele vivia dizendo que era estéril. A tonta aqui acreditou e não se preveniu. Ele era casado com a Zilda há tanto tempo e ela nunca engravidou. Tive que fazer exame de DNA pra ele acreditar. O cara

10 "De mulher para mulher" é o slogan/vinheta da loja Marisa. 
chorou feito criança. Ser pai era tudo que ele mais queria na vida. - Se for homem, vai se chamar Sebastião, como meu velho. O coitado morreu sem a alegria de ter um neto. Lá do céu, ele vai gostar da homenagem.

O Cícero se dividia entre a minha casa e a casa de Zilda, a mulher oficial. A coitada nunca desconfiou de nada. Ao me ver de barriga, veio me cumprimentar com os olhos cheios de lágrimas: "pena que esse sonho eu não vou realizar. O Cícero é estéril".

Quando a bolsa estourou, o jeito foi pedir pra Dora me levar pro hospital. O banana mandou dizer que não podia sair no meio do ensaio. Hoje minha filha completa sete dias e até agora o Cícero não deu as caras. Só que dessa vez ele se lascou. Primeiro, porque a escola fez um fiasco na avenida e caiu pro grupo de acesso. Segundo, porque o filho que ele tanto queria nasceu mulher e se chama Berenice, como minha mãe. Lá de cima, a velha deve estar tirando o maior sarro da cara do seu Sebastião, o pai do filho da puta.

(LEITE, 2014, p. 65)

O conto dado compõe a segunda parte do livro Cachorros (2014), intitulada [Bananas] ${ }^{11}$. O modo de compor o livro, a partir do título, do todo e das partes, conduz o leitor a um campo semântico de nossa cultura bastante conhecido de todos, ou seja, a utilização da linguagem para significar a intenção da autora é bastante transparente e não opaca, trabalha com a automatização linguística, distante das orientações formalistas que evidenciavam a literariedade do texto literário pelos mecanismos de estranhamento e desautomatização da linguagem (Eikhenbaum, 1970). ${ }^{12}$ Cachorro e Banana, longe de outros aspectos semânticos que possam significar, são rápida e diretamente correlacionados ao sujeito masculino (não importando sua cor, classe social, credo professado, grau de instrução etc.). Qualquer leitor e/ou ouvinte, em nossa cultura, decodificaria os signos sugeridos, dentro do contexto com o qual estamos trabalhando, como interpretantes do sujeito homem, porque em determinadas situações de provar ou não se esse sujeito é - naquilo que Sócrates Nolasco, em 1995, apontou, como - "homem de verdade". Para o primeiro termo, obtém-se o sentido de homem de mau caráter, "pegador", canalha, que se relaciona com qualquer mulher sem critério algum de escolha; para o segundo, o significado obtido é o de homem sem atitude, covarde, "mole", que não tem conceito para não assumir o que defenderia (caso optasse por defender). ${ }^{13}$

\footnotetext{
${ }^{11}$ A primeira parte do livro é intitulada [Cachorros], com doze contos. A segunda parte, [Bananas], contém seis contos. ${ }^{12}$ Tenho consciência de que esses dois mecanismos da literariedade foram pensados e utilizados, em sua primazia, para a leitura e análise de poemas ou de textos poéticos, não de textos em prosa. Mas me aproprio aqui da visão geral do que se entendia por literatura autônoma (não por poema ou conto, por exemplo) para chegar ao meu argumento maior que se concentra em torno da noção de anti-arte.

${ }^{13}$ Os sentidos dados aos termos em análise são uma síntese de consultas a dicionários online vários e impressos, unicamente com a intenção de auferir os reais efeitos semânticos atribuídos aos termos do conto em tela.
} 
O livro, para além das questões de "ordem feminina" ou "feminista" (ou mesmo das mulheres em si), endereça discursos capazes de desestabilizar visões (ou acirrar mesmo visões) sobre tipos de homens em relacionamentos com suas mulheres. São estas que narram, que interpretam, que anunciam e descrevem os tipos masculinos - cachorro e banana - com os quais se envolvem, mesmo quando, contrariando, também, certas "etiquetas" culturais: há várias personagens nos contos que sobrevivem em companhia desses homens, mas não se sujeitam aos modos de viver relações a dois como gostariam esses sujeitos masculinos.

O título do conto brinca com o duplo aspecto semântico do termo no contexto em que se insere: a surdez do personagem Cícero (marido de Zilda), companheiro extraconjugal da protagonista, que não atendeu ao chamado desta na hora em que a bolsa estourou (fez "ouvido de mercador" e, logo, por isso, surdo); e o instrumento de percussão surdo, tocado por Cícero, integrante da bateria de uma escola de samba. O termo, no conto, encerra um sentido que pode ser percebido numa relação polar ou na contramão semântica: o surdo tocado por Cícero faz barulho, tornando-o, quiçá, surdo aos apelos e à voz da amante, na hora do nascimento do primeiro filho deles.

A protagonista vive uma relação não oficial com o marido de uma vizinha. Apesar da relação com um homem casado, sua consciência não é afetada nem ela rumina a situação, seja avaliando, julgando ou tornando-se menor, inferior. Vive o relacionamento de forma pacífica - mas escondida. Todo o problema desse relacionamento reside no fato de Cícero ser um "banana". A atitude tomada pela protagonista para "não descer do salto" vem como forma de "vingança". Sete dias após o nascimento da filha, Cícero ainda não havia aparecido para saber do estado da mãe da filha nem para conhecer esta. A protagonista, então, enuncia: "Só que dessa vez ele se lascou". Na cultura brasileira, a expressão linguística "se lascar/lascar-se" e seus equivalentes têm significado agressivo, violento, pejorativo. Cícero "se lascou" porque, primeiro, a escola na qual tocava surdo, foi rebaixada para o grupo de acesso (apesar do maior barulhão feito), depois, porque o filho tão desejado nasceu "menina"; terceiro, uma vez que o recém-nascido não nasceu menino e deveria se chamar Sebastião, em homenagem ao pai do genitor, recebeu o nome de Berenice, em homenagem à mãe da protagonista. Por fim, ressabiada com o comportamento do amante, a protagonista ainda chama Cícero de "ffilho da puta".

O conto, então, traz à tona uma personagem que não se enquadra no esquema tático da ordem machista. A construção de famílias, por exemplo, é examinada à luz de uma perspectiva crítica e realista: casal heterossexual com filho, sem serem casados, resultado de uma estabilidade relacional extraconjugal (Cícero e a protagonista), casal heterossexual sem filhos (Cícero e Zilda) e essas duas formas de viver relacionamentos a partir do conceito família estão distantes 
daqueles conceitos e valores requeridos pela ordem patriarcal e machista, conforme vemos nos contos de Cunha. ${ }^{14}$ As personagens de Leite vivem os dilemas pertinentes a esses tipos de relações, mas nem por isso se culpam, são derrotadas, fracassam no trabalho, na vida pessoal. Vivem uma constante luta pela vida, independentemente do modo de vida escolhido para estar com o outro do seu afeto. As protagonistas desta escritora são "traídas" em suas relações de afeto como também traem, sem que o valor "traição" seja motivo de repulsa ou julgamento inferior que as torna menores, submissas, fracassadas. Eis o conto "Amarilis":

Quando Saul me comprou, achou que fez um ótimo investimento. Preço módico, negócio de ocasião. Pra garantir a posse, cercou-me com muro alto. Como se não bastasse, passou arame farpado. Era pouco: eletrificou os fios. Só então dormiu sossegado. Hoje, quando me vê invadida, brada aos céus, furioso:

- Maldita reforma agrária. Repartir o que é meu com quem não é de direito.

A depender dele e eu seria um lodo de água salobra cheia de escorpiões e pregos enferrujados. Improdutiva para sempre.

(LEITE, 2002, p. 43)

A relação de infidelidade, neste caso, é por parte da mulher e sentida pelo homem que relaciona o script ou alegoria da "traição" (pela mulher) a uma reforma agrária em que haveria, inicialmente, uma espécie de invasão (penetração sexual) da terra (corpo da mulher) e, posteriormente (no plano da ideia), a divisão (mesmo referente ou objeto para mais de uma parte ou posseiro: homem) da terra entre as demandas reivindicantes. A mulher, neste jogo de afetos e sexo, ao analisar a situação em que se encontrava (comprada a preço baixo, cercada por muro alto, arame farpado e eletrificado), ironiza esse esquema tático esperado pelo homem que a queria na lógica contrária a que defende: ele espera A Mulher, enquanto ela já se construiu na e pela lógica dAs Mulheres.

Como o leitor há de perceber, as mulheres de Leite encontram como alternativas para suas vidas as rotas de fuga que colidem com os scripts de gênero engessados pela ordem hegemônica e endereçados às mulheres para que se comportem como um único corpo, orgânico, reprodutor, todo afeto e todo censura, iluminista e cartesiano. Longe de ficarem caladas e de serem silenciadas, essas mulheres falam, as personagens mulheres sinalizam o tempo em que estamos vivendo, décadas finais do século 20 e século 21. Elas reivindicam para si modos distintos de sentir e viver o sexo, a sexualidade, o gênero; de perceber o outro de seu afeto; de entender e resolver questões corporais sem os interditos religiosos, de viver a solidão como uma prerrogativa afirmativa e necessária para muitos sujeitos.

\footnotetext{
${ }^{14}$ Esse tipo de relacionamento - triângulo amoroso - existiu em outras épocas (os estudos de Del Priore apontam isso). Todavia, diferentemente de interpretação de teor moral negativa, a relação extraconjugal, aqui, é assumida pela protagonista sem grandes traumas, salvo o fato da esposa de seu amante ser sua amiga e não saber da "traição".
} 
Para além dessas questões, o próprio conceito de gênero, dos usos do sexo e as compreensões sobre a sexualidade são distribuídos nessa literatura mais atual diferentemente daquela que arrolava unicamente um gênero binário (masculino e feminino), um sexo binário (pênis e vagina) e uma sexualidade binária (heterossexual $=$ homem + mulher). Aqui, seja em Cachorros (2014) ou em outros textos de mulheres, a noção de gênero é ampliada, assim como a experiência com o corpo, o sexo e a sexualidade. Em As filhas de lilith (2009), de Pedrosa, no poema "angélica", a combinação mulher-corpo-sexo-sexualidade é compreendida de uma forma autônoma, liberta de amarras preconceituosas e engessadas: "o pênis de angélica/era de plástico/passou a vida a esfregar-se no espelho//eis a sina/mulher ou homem//injusto desígnio/para quem precisa-se/inteiro por dentre as coxas//voz rouca sob os lençóis/desejo de iguais/ porra/bocetas também são objetos de encaixe" (p. 17).

No poema "angélica" o sexo não define um gênero nem um único modo de o sujeito se revestir de uma sexualidade. Os desejos desencaixam as peças engessadas em modelos programados para A Mulher. As Mulheres, então, tornam cada dia mais obsoleta essa visão encarceradora, objetal e passiva que só consegue ver nelas o singular. No poema "melissa"15 (p. 45) tem-se a história de um garoto nascido "loiríssimo e com olhos azuis" em que "tudo nele era lindo/ aqueles rapazes o desejavam/de verdade e não sabiam//nunca se ouviu falar de bunda/igual àquela e de pentelhos/louros quais aqueles". O corpo de melissa (sic), segundo a voz lírica do poema, foi feito "para homens que gostam de mulher", por isso, "em setembro do ano passado/polaca [melissa]/conseguiu fazer sua cirurgia/de mudança de sexo".

Os gêneros, aqui e em outras escrituras de mulheres, respeitam a diversidade e as diferenças, distanciando-se do modelo arcaico que encerrava todos apenas no binário, para possibilitar, entender e respeitar a experiência transmulher vivida por polaca-melissa: a experiência transexual modifica a noção de gênero, liberta as pessoas da relação clássica sexo-gênero-sexualidade, ou seja: nascer com pênis não evoca naturalmente, ou numa relação/proporção direta, a função homem e o desejo heterossexual, assim como o nascer com vagina não implica uma relação natural e direta com o assumir a função mulher e heterossexual. Grande achado das obras de autoria feminina, no tempo sincronizado aqui discutido, é a evolução e mudanças percebidas entre a concepção dA Mulher às Mulheres. ${ }^{16}$

\footnotetext{
${ }^{15}$ Por questão de extensão do poema (21 estrofes e 64 versos), transcrevo apenas trechos significativos do poema para corroborar a ideia sustentada ou desenvolvida, apesar de ter consciência que todo o poema é de fundamental importância para a construção desta mesma tese.

${ }^{16}$ Toda a discussão aqui entabulada teve também como referentes literários as obras Henrique (2001), de Leilla; Dez (quase) amores (2009), de Tajes; Preces e orgasmos dos desvalidos (2005), de Limeira; Dores de amor romântico (2005), de Young; A paixão de Lia (1995), de Milan; Marias (1999), de Azevedo; Café expresso blackbird (2006), de Benitez, dentre outras autoras e obras das mesmas autoras citadas.
} 
Em determinados projetos de autoria estética encontramos propostas como a de Cláudia Tajes, em que sua personagem, Maria Ana, é uma mulher sempre disponível para as aventuras amorosas avulsas, enquanto não encontra um par fixo. Dôra Limeira constrói mulheres também avessas às normas sociais, incluindo nesse livro em destaque mulheres maduras, sexagenárias até, dispostas a relacionamentos provisórios, rápidos. Tanto Fernanda Young quanto Greta Benitez colocam em cena mulheres citadinas aventureiras no amor conjugado no diverso, no plural. Beth Milan e Janaína Azevedo exibem mulheres questionadoras de seu lugar social, rasurando papeis em que se encontram, performando outras mulheres, distantes dos modelos sociais. Por fim, Álex Leila, subverte a configuração de mulher em Henrique (2001), ao criar Maria Alice, personagem que se envolve em relações de afeto e sexo com homens que se relacionam no mesmo nível com outros homens, sem que a carga negativa desse modo de estar no mundo afete essa mulher.

\section{Considerações provisórias sobre a anti-arte de resistência}

A passagem discursiva “d'A mulher às Mulheres”, conforme o título do livro das estudiosas de base feminista, apontado desde o início dessa discussão, não aconteceu sem conflitos, sem tensões teóricas. Em muitas ocasiões, sobretudo, quando as escrituras de mulheres ganham os espaços acadêmicos, pesquisadores de várias perspectivas interpretativas emitem opiniões sobre os eventos desencadeados, vez que boa parte da academia, principalmente daquela que lida diariamente com o texto literário, tem formação clássica e canônica desta "arte". Isso significa dizer que os modos de escrever e de trazer à tona estórias e temas são questionados sob vários ângulos: estilo, compromisso com parâmetros canônicos, linguagem utilizada, modos de materializar em linguagens o evento narrado.

Essa literatura de mulheres, sob o ângulo que analiso, comparo-a a visão pós-autônoma defendida por Ludmer (2010), que compreende, numa perspectiva mais global e atual, literaturas ou escritas que não se querem literárias porque não passam pelo crivo da "literariedade", por exemplo: são escritas produzidas por autoras, vendidas e com públicos leitores, mas que, pela intenção, linguagem e modo de representação, principalmente por estabelecerem um hiperrealismo na linguagem, distanciam-se do conceito clássico de literatura, mesmo sem deixar de ser literatura. $\mathrm{O}$ foco de muitas mulheres (e homens) que escrevem é demarcar um espaço político, um lugar de fala.

Essa percepção que Ludmer tem sobre o evento literário associa-se ao conceito de artivismo, de Chaia (2007), quando elide arte com ativismo político: "Neste forte envolvimento social, tem-se, assim, reduzida a autonomia da arte e, em contrapartida, amplia-se a relação entre ética e estética" (p. 101). A linguagem e os temas trazidos à tona pelas autoras mulheres, entendo, somatizam esse 
momento e essa concepção: longe de investir na produção de uma obra atrelada teoricamente a um conceito clássico e distante das atuais estruturas sociais e culturais, abandona-se esse pilar que vigorou ontem e abraça-se o modus operandi que sintoniza, sem perda de valor simbólico, a ideia de arte e ativismo político, de estética e de ética, visto por alguns estudiosos como anti-arte.

A anti-arte, então, no sentido das escrituras de mulheres, não seria aquela discutida por Moutinho (2001), quando faz uma recensão literária em torno do conceito de kitsch vinculando-o à noção de anti-arte, também concebida como “mau gosto" por Dorfles (1989). Na perspectiva usada aqui, anti-arte está para aquela concepção atribuída por Oiticica (1986), quando fala da "Nova Objetividade". Ao elencar os seis elementos do "manifesto" em que formula "um estado da arte brasileira de vanguarda atual [à época que escreveu]", coloca como última característica, a de número 6 , o "ressurgimento e novas formulações do conceito de anti-arte" (p. 84).

Dessa forma, pode-se chegar à conclusão de que as escritas de autoria feminina, conforme vimos defendendo ao longo do artigo, são anti-arte na via afirmativa do conceito: pela linguagem utilizada; pelos temas elaborados e trazidos à tona; pelo distanciamento da estética clássica e canônica; pela atualização das linguagens e de suas correlações com outras mídias, suportes e modos de as pessoas se subjetivarem, rediscutindo conceitos, valores e estilos de vida. Se tivermos em mente que as protagonistas das obras de mulheres aqui trazidas à tona se colocam como sujeitos de si, autônomas pela equidade de gênero como marca do nosso momento histórico, falando uma linguagem cotidiana, próxima das relações (inter)pessoais do dia a dia, abordando problemas tabus e relacionados ao corpo, ao sexo, às sexualidades, aos modelos vários de família, aos gêneros não fixos nem binários, é exato dizer que tratam de um teor, de certa forma, ativista: "De imediato, o ativismo cultural tende a aproximar-se da anti-arte, ao eliminar o objeto artístico em favor da intervenção social inspirada pela estética e ao desconsiderar a contemplação em benefício do envolvimento da comunidade" (CHAIA, 2007, p. 10).

O leitor há de concordar que a visão clássica, estética e de contemplação relacionada à literatura - canônica, logo - só podia possibilitar um modelo de pessoa, porque centrado na ideia cartesiana (binária) e iluminista de sujeito, de gênero, de sexo, de sexualidade, inclusive de escrita: às mulheres era negado o desejo e o fazer literários. As autoras que desenham e denunciam modelos patriarcais de mulheres, talvez por terem ainda suas bases culturais mais fortes retidas e engessadas no tempo e no espaço em que foram educadas, conseguem sair desse parâmetro paulatinamente: antes dos anos 1980, a meu entender, elas tendem a traduzir culturalmente nas suas escrituras mulheres únicas, modelares, polidas, 
submissas, castas, de linguagem formal e clean, casadoiras, parideiras (salvo as exceções). Mesmo quando apontam para uma fuga dessa regra de representação, é o modelo clássico, conservador que assegura a imagem das personagens.

Por fim, diferem das autoras que esboçam estórias de mulheres no pós1980: estas traduzem culturalmente em suas escritas mulheres diversas, diferentes quanto ao credo, à cor, ao desejo sexual, à condição social e grau de instrução, local de habitação; mulheres polidas e mal educadas, mulheres que reivindicam constantemente a igualdade de direitos de gênero; mulheres castas e infiéis que se utilizam de linguagens ora formal ora do cotidiano ou, até, de baixo calão. No geral, são mulheres que se distanciam dos modelos burgueses clean, casam quando querem, por vontade própria e reciprocidade, usando do corpo para gozar, gestar, abandonar-se, trair o outro e tantas outras funções, sem que estas características funcionem numa ordem ou gradação: podem acontecer em conjunto ou apenas individualmente. Quando entendemos esses dois modos distintos - apesar de alguns momentos, localizados, percebermos os dois modos sendo operados em uma mesma escrita e tempo - dizemos tratar-se de mulheres que existem sob formas diferentes de abordar a si, resistindo e questionando os lugares fixos das culturas no que tange às questões de gênero e aos processos de escrituras de mulheres.

\section{Referências}

AZEVEDO, Janaína. Marias. João Pessoa: Editora da UFPB, 1999.

BENITEZ, Greta. Café Expresso Blackbird. São Paulo: Landy, 2006.

BRANDÃO, Izabel (Org.). O corpo em revista: olhares interdisciplinares. Maceió: EdUFAL, 2005.

BUTLER, Judith. Problemas de Gênero: feminismo e subversão da identidade. Rio de Janeiro: Civilização Brasileira, 2003.

CAVALCANTI, Ildiney; LIMA, Ana Cecília \& SCHNEIDER, Liane (Orgs.). Da mulher às mulheres: dialogando sobre literatura, gênero e identidades. Maceió: EdUFAL, 2006.

CHAIA, Miguel. Artivismo - política e arte hoje, Revista Aurora, n. 1, São Paulo, 9-11, 2007.

COELHO, Nelly Novaes. Dicionário crítico de escritoras brasileiras. São Paulo: EdUSP, 2002.

CORTÁZAR, Julio. Valise de cronópio. São Paulo: Perspectiva, 2006.

CUNHA, Helena Parente. Falas e falares. Santa Catarina: Editora Mulheres, 2011.

CUNHA, Helena Parente. Os provisórios. Rio de Janeiro: Tempo Brasileiro, 1998. 
DEL PRIORE, Mary. História do amor no Brasil. 2. ed. São Paulo: Contexto, 2006.

DORFLES, Gillo. Novos ritos, novos mitos. Lisboa: Edições 70, 1989.

EIKHENBAUM, Boris. Teoria da literatura. Formalistas russos. Porto Alegre: Globo, 1970.

FACIOLINCE, Hector Abade. Basura. Madrid: Lengua de Trapo, 2000.

HALL, Stuart. A identidade cultural na pós-modernidade. Trad. Tomás Tadeu da Silva. Rio de Janeiro: DP\&A, 1997.

HOLANDA, Heloisa Buarque de (Org.) Tendências e impasses: o feminismo como crítica da cultura. Rio de Janeiro: Rocco, 1994.

KHOTE, Flavio René. Narrativa trivial. Brasília: Editora da UnB, 1994.

LEILLA, Álex. Henrique. Salvador: Domínio Público, 2001.

LEITE, Ivana Arruda. Cachorros. São Paulo: V. de Moura Mendonça, 2014.

LEITE, Ivana Arruda. Falo de mulher: Rio de Janeiro: Ateliê Editorial, 2006.

LIMIERA, Dôra. Preces e orgasmos dos desvalidos. João Pessoa: Manufatura, 2005.

LINK, Daniel. La ansiedad: novela trash. Buenos Aires: El cuenco de plata, 2004.

LUDMER, Josefina. Literaturas pós-autônomas, Sopro, v. 20, Desterro, 1-4, 2010.

MILLAN, Beth. A paixão de Lia. 2. ed. São Paulo: Globo, 1995.

MOUTINHO, Ana Viale. Sincronizando o Kitsch, Revista Melibra, n. 8, Minho, 151154, 2001.

NOLASCO, Sócrates. A desconstrução do masculino. Rio de Janeiro: Rocco, 1995.

OITICICA, Hélio. Aspiro ao grande labirinto. Rio de Janeiro: Rocco, 1986.

PEDROSA, Cida. As filhas de lilith. Ilustrações: Tereza Costa Rego. Rio de Janeiro: Calibán, 2009.

ROMÃO, Luiza. Sangria. São Paulo: Edição do Autor (Selo do Burro), 2017.

TAJES, Cláudia. Dez (quase) amores. Porto Alegre: L\&PM, 2009.

TOURAINE, Alain. O mundo das mulheres. Petrópolis: Vozes, 2010.

XAVIER, Elódia. Declínio do patriarcado: a família no imaginário feminino. Rio de Janeiro: Record: Rosa dos Tempos, 1998.

XAVIER, Elódia. Que corpo é esse? O corpo no imaginário feminino. Santa Catarina: Editora Mulheres, 2007.

YOUNG, Fernanda. Dores de amor romântico. Rio de Janeiro: Ediouro, 2005. 